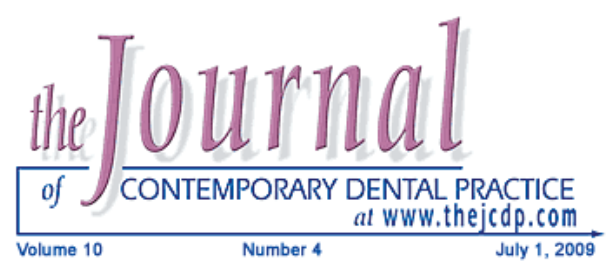

\title{
Teething Problems and Parental Beliefs in Nigeria
}
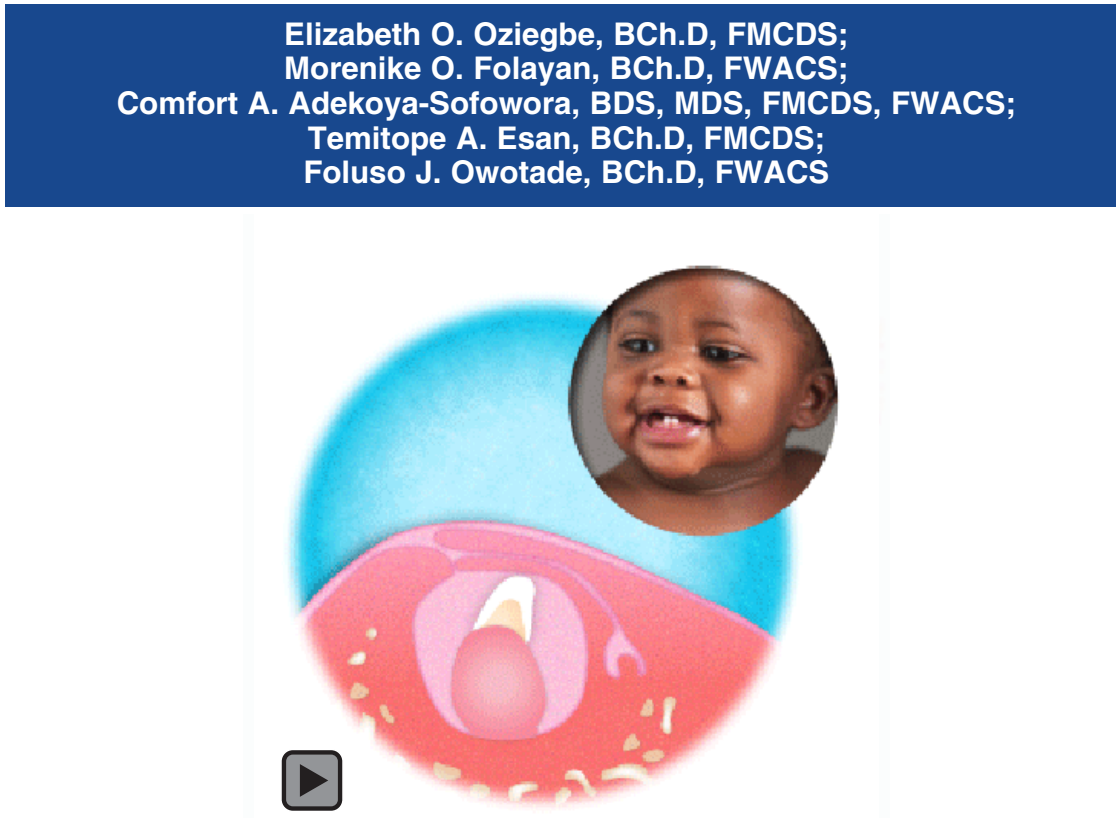

Abstract

Aim: To determine signs and symptoms associated with teething, parental beliefs about teething, and the effects of socioeconomic status on teething in Nigerian children.

Methods and Materials: A cross-sectional study consisting of 1,013 mothers of children between the ages four to 36 months who visited the immunization clinics at the Community Health Centres in Ife Central and Ife East Local Government Areas. Data was analyzed using STATA (Intercooled release 9) for Windows.

Results: A total of 765 mothers $(75.5 \%)$ reported systemic signs and symptoms in their children. Fever $(51.8 \%)$, diarrhea (12.5\%), and vomiting (2.9\%) were the most prevalent symptoms and signs reported. Teething problems were reported by $60 \%$ of mothers from a high socioeconomic class, as well as $76.7 \%$ and $77.9 \%$ from middle and low socioeconomic classes, respectively. Interestingly, $65.5 \%$ of mothers believed teething should be accompanied with systemic signs and symptoms such as fever (42.1\%), diarrhea (13.9\%), and vomiting (0.6\%). No significant difference was noted between breastfeeding status, gender of the child, and reported systemic signs and symptoms noticed by the mothers.

Conclusion: Most mothers in the study reported signs and symptoms adduced to teething in their children irrespective of their beliefs. Fever ranked highest of the signs and symptoms reported. Mothers of children from the high socioeconomic class reported fewer teething symptoms. Breastfeeding status and gender of the child had no effect on teething problems in the children studied.

(c) Seer Publishing 
Clinical Significance: Most signs and symptoms adduced to teething by parents may actually be due to underlying infections. Thus, there is a need to rule out occult infection during the tooth eruption period.

Keywords: Eruption, teething, fever, primary, dentition

Citation: Oziegbe EO, Folayan MO, Adekoya-Sofowora CA, Esan TA, Owotade FJ. Teething Problems and Parental Beliefs in Nigeria. J Contemp Dent Pract 2009 July; (10)4:075-082.

\section{Introduction}

The appearance of the first set of teeth in children is an important milestone in the development of the child. ${ }^{1}$ Usually eruption of the teeth causes little or no distress to children. Teething is described as a harmless, normal physiological phenomenon. ${ }^{2}$ However, myriads of myths and misconceptions continue about signs and symptoms of teething such as erroneous beliefs by both mothers and health workers relating fever and diarrhea to teething. ${ }^{3.5}$ Reports on local and systemic signs and symptoms associated with teething appeared as far back as the 5th century. ${ }^{6}$ While some investigators ${ }^{7,8}$ believe teething is associated with local irritation and a whole host of other symptoms, others ${ }^{3}$ disagree.

Unfortunately, the normal developmental process makes interpretation of research on teething particularly challenging. ${ }^{2}$ One example is the normal salivary gland development which occurs at about two to three months of age when the salivary glands of infants begin functioning which contributes to constant drooling, which mothers may misinterpret as a sign of teething. ${ }^{2}$ Nocturnal awakening occurring around eight or nine months of age when infants develop a sense of object permanence and call out to their parents is another normal developmental event mothers can erroneously assume is a symptom of teething. ${ }^{2}$ At approximately six months of age, when the primary teeth are about to erupt, maternal antibodies upon which young children depend begins to decrease while they build up their own antibodies which are not yet sufficient to defend them against infections. ${ }^{2-5}$ Furthermore, this same age is when children begin to crawl and place unclean objects in their mouths which can introduce pathogens into their bodies and may lead to gastrointestinal disturbances such as diarrhea, vomiting with an associated increase in body temperature. ${ }^{3.5}$

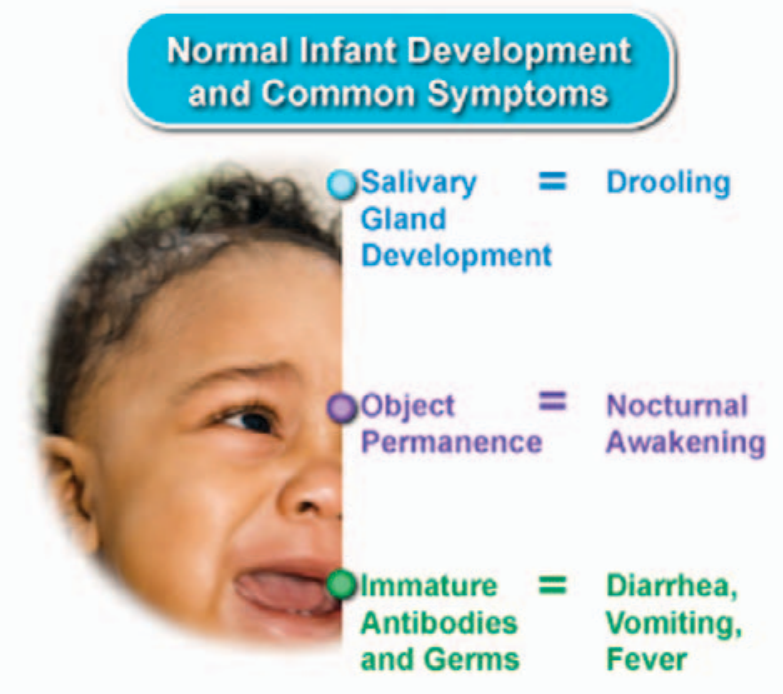

Myths and misconceptions about signs and symptoms of teething continue to abound and the general public's interest in the subject remains high. Despite the research that has been done on teething problems controversy persists with regard to a conclusive opinion of what constitutes true teething symptoms.

This study attempted to contribute to the vast amount of literature on the subject matter by specifically aiming to determine the association between teething problems, the socioeconomic status, and the breastfeeding status of the child.

\section{Methods and Materials}

The study population consisted of mothers of all consecutive clinically healthy full term babies, infants, and preschool children who visited immunization clinics located in a suburban population in Ile-Ife, Nigeria over a period of six months. The health centers provide immunization and health care services for children who are under 16 years of age. 


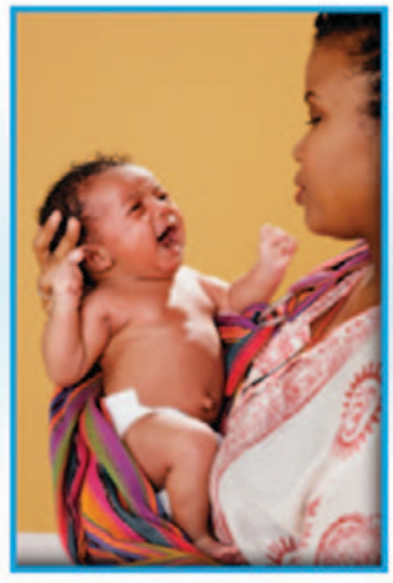

Questionnaires were administered to the accompanying mother by an interviewer following the acquisition of written consent to participate in the study. The first part of the questionnaire elicited biographical information about the child participant including age, gender, address, place of birth, socioeconomic status, and breastfeeding status.

The socioeconomic status for the purpose of this study was obtained using a standard occupation classification designed by Office of Population Census and Surveys, London (OPCS 1991). ${ }^{9}$ For the purpose of this study, these standard occupation classes were grouped into social classes follows:

- High Socioeconomic Class - Classes I and II

- Middle Socioeconomic Class - Classes III (Non manual) and III (Manual)

- Low Socioeconomic Class - Classes IV and V

Breastfeeding status was defined based on the duration of breastfeeding of the child by classifying the children into two groups as follows:

- Group 1 were those fed on breast milk only for the first six months of life.

- Group 2 were those who received breast milk for less than six months or those who breastfed with some form of supplementary feeding such as water and intravenous infusion during the first six months of life.

All the children in this study were breastfed in one form or the other.

The second part of the questionnaire elicited information on the parents' beliefs about teething problems, while the third part elicited information on the parents' observation of teething symptoms during eruption of the teeth.

Data were analyzed using Intercooled release 9 of STATA for Windows (Statacorp, College Station, TX, USA). The analysis included frequencies and cross tabulations. The association between discrete variables was tested using the Chi-square test while associations between continuous variables were tested using the Student $t$ test and the multiple analysis of variance (ANOVA). Statistical significance was inferred at $p<0.05$.

\section{Results}

A total number of 1,013 parents responded to the questionnaire. The age of the children ranged from four to 36 months with the mean age ( \pm standard deviation) of $19.04 \pm 9.34$ months. There were 514 boys (50.7\%) and 499 girls (49.3\%). The mean age for boys was $19.24 \pm 9.59$ months and $18.83 \pm 9.09$ months for girls. There was no statistically significant difference between the mean ages $(p>0.05)$.

Out of 1,013 mothers interviewed, 765 mothers $(75.5 \%)$ reported signs and symptoms in their children while $248(24.5 \%)$ of the mothers experienced no teething problems in their children. When all signs and symptoms seen by mothers in the children during teething were ranked, fever was the most prevalent (51.8\%), followed by diarrhea (12.5\%), and then vomiting $(2.9 \%)$ (Table 1).

Sixty percent of mothers from the high socioeconomic class reported teething problems in their children while $76.7 \%$ and $77.9 \%$ from the middle and low socioeconomic classes, respectively, reported teething problems. There was a statistically significant difference in the symptoms reported from the different socioeconomic classes. Fewer symptoms were reported by those in the high socioeconomic class when compared to those in the middle socioeconomic class $(p<0.05)$ and the low socioeconomic class $(p<0.05)$. There was, however, no significant difference in the reports for children in the middle and low socioeconomic classes $(p>0.05)$ (Table 2). 
Table 1. Ranking of signs and symptoms of teething as reported by mothers in their children.

\begin{tabular}{|c|c|c|c|c|c|c|c|c|}
\hline \multicolumn{3}{|c|}{ First Rank } & \multicolumn{3}{|c|}{ Second Rank } & \multicolumn{3}{|c|}{ Third Rank } \\
\hline Signs and Symptoms & No & $\%$ & Signs and Symptoms & No & $\%$ & $\begin{array}{l}\text { Signs and } \\
\text { Symptoms }\end{array}$ & No & $\%$ \\
\hline Fever & 525 & 51.8 & Diarrhea & 127 & 12.5 & Vomiting & 29 & 2.9 \\
\hline None & 248 & 24.5 & Fever & 87 & 8.6 & Diarrhea & 25 & 2.5 \\
\hline Diarrhea & 76 & 7.5 & Vomiting & 70 & 6.9 & Fever & 23 & 2.3 \\
\hline Cough & 69 & 6.8 & Cough & 69 & 6.8 & Cough & 21 & 2.1 \\
\hline Boil/skin rash & 30 & 3.0 & Catarrh & 44 & 4.3 & Catarrh & 10 & 1.0 \\
\hline Vomiting & 25 & 2.5 & Boil/skin rash & 29 & 2.9 & Boil/skin rash & 8 & 0.8 \\
\hline Catarrh & 18 & 1.8 & Measles & 7 & 0.7 & Gum bleeding & 4 & 0.4 \\
\hline Measles & 11 & 1.1 & Sleeplessness & 5 & 0.5 & Sleeplessness & 3 & 0.3 \\
\hline Eye discharge & 3 & 0.3 & Drooling saliva & 3 & 0.3 & Measles & 1 & 0.1 \\
\hline $\begin{array}{l}\text { Increase oral } \\
\text { temperature }\end{array}$ & 2 & 0.2 & Gum bleeding & 3 & 0.3 & Eye discharge & 1 & 0.1 \\
\hline Malaria & 2 & 0.2 & Eye discharge & 1 & 0.1 & Malaria & 1 & 0.1 \\
\hline Ear discharge & 1 & 0.1 & Thrush & 1 & 0.1 & None & 0 & 0 \\
\hline Drooling saliva & 1 & 0.1 & None & 0 & 0 & $\begin{array}{l}\text { Increased oral } \\
\text { temperature }\end{array}$ & 0 & 0 \\
\hline Pale & 1 & 0.1 & $\begin{array}{l}\text { Increased oral } \\
\text { temperature }\end{array}$ & 0 & 0 & Ear discharge & 0 & 0 \\
\hline Gum bleeding & 0 & 0 & Malaria & 0 & 0 & Drooling saliva & 0 & 0 \\
\hline Sleeplessness & 1 & 0.1 & Ear discharge & 0 & 0 & Pale & 0 & 0 \\
\hline Thrush & 0 & 0 & Pale & 0 & 0 & Thrush & 0 & 0 \\
\hline
\end{tabular}

Table 2. Signs and symptoms of teething reported in the children according to socioeconomic class.

\begin{tabular}{|l|c|c|c|}
\hline \multirow{2}{*}{ Signs and Symptoms } & \multicolumn{3}{c|}{ Socioeconomic Class } \\
\cline { 2 - 4 } & High & Middle & Low \\
\hline No symptoms & 42 & 104 & 102 \\
\hline Child with symptoms & 63 & 342 & 360 \\
\hline Total & 105 & 446 & 462 \\
\hline
\end{tabular}


Table 3. Ranking of mothers beliefs on teething.

\begin{tabular}{|c|c|c|c|c|c|c|c|c|}
\hline \multicolumn{3}{|c|}{ First Rank } & \multicolumn{3}{|c|}{ Second Rank } & \multicolumn{3}{|c|}{ Third Rank } \\
\hline Perception & No & $\%$ & Perception & No & $\%$ & Perception & No & $\%$ \\
\hline Fever & 426 & 42.1 & Diarrhea & 40 & 3.9 & Diarrhea & 139 & 13.7 \\
\hline No symptoms & 360 & 35.5 & Vomiting & 32 & 3.2 & Fever & 86 & 8.5 \\
\hline Diarrhea & 82 & 8.1 & Cough & 26 & 2.6 & Vomiting & 62 & 6.1 \\
\hline Not sure & 40 & 3.9 & Boil/rash & 24 & 2.4 & Cough & 54 & 5.3 \\
\hline Vomiting & 31 & 3.1 & Fever & 18 & 1.8 & Boil/rash & 28 & 2.8 \\
\hline Cough & 19 & 1.9 & Catarrh & 10 & 1.0 & Catarrh & 11 & 1.1 \\
\hline Boil/rash & 11 & 1.1 & Irritability & 8 & 0.8 & Gum swelling & 6 & 0.6 \\
\hline Catarrh & 8 & 0.8 & Eye discharge & 4 & 0.4 & Irritability & 5 & 0.5 \\
\hline Gum swelling & 6 & 0.6 & Gum swelling & 3 & 0.3 & \begin{tabular}{|l} 
Increase oral \\
temperature
\end{tabular} & 4 & 0.4 \\
\hline Malaria & 6 & 0.6 & $\begin{array}{l}\text { Increase oral } \\
\text { temperature }\end{array}$ & 1 & 0.1 & Drooling of saliva & 3 & 0.3 \\
\hline $\begin{array}{l}\text { Increase oral } \\
\text { temperature }\end{array}$ & 5 & 0.5 & No symptoms & 0 & 0 & Malaria & 1 & 0.1 \\
\hline Irritability & 4 & 0.4 & Not sure & 0 & 0 & Measles & 1 & 0.1 \\
\hline Measles & 3 & 0.3 & Malaria & 0 & 0 & Eye discharge & 1 & 0.1 \\
\hline Pain & 2 & 0.2 & Measles & 0 & 0 & No symptoms & 0 & 0 \\
\hline IIIness & 1 & 0.1 & Pain & 0 & 0 & Not sure & 0 & 0 \\
\hline Infection & 1 & 0.1 & Illiness & 0 & 0 & Pain & 0 & 0 \\
\hline Lower immunity & 1 & 0.1 & Infection & 0 & 0 & IIIness & 0 & 0 \\
\hline Drooling of saliva & 0 & 0 & Lower immunity & 0 & 0 & Infection & 0 & 0 \\
\hline Eye discharge & 0 & 0 & $\begin{array}{l}\text { Drooling of } \\
\text { saliva }\end{array}$ & 0 & 0 & Lower immunity & 0 & 0 \\
\hline
\end{tabular}

A total of $1,006(99.31 \%)$ out of 1,013 mothers interviewed about their beliefs related to teething responded. The others chose not to participate in the study for unknown reasons. Of the participants, 646 mothers (65.5\%) believed teething should be accompanied with systemic signs and symptoms. Table 3 shows the ranking of expected signs and symptoms believed to be associated with teething. Fever (42.1\%) had the highest ranking, followed by diarrhea (13.9\%), and then vomiting $(0.6 \%)$. On the other hand,
360 mothers (35.5\%) believed there should be no teething problems.

There was a statistically significant difference in the respondents' reported belief about teething symptoms based on their socioeconomic class $(p<0.05)$. Significantly fewer mothers in the high socioeconomic class believed teething should be accompanied by signs and symptoms when compared to respondents in the middle socioeconomic class $(p<0.05)$ and the low 
socioeconomic class $(p<0.05)$. There was no observed difference in the responses of those in the middle and high socioeconomic classes ( $p>0.05$ ) (Table 4).

Of the 360 respondents who believed there should be no teething problems, significantly more mothers reported observations of teething symptoms during the eruption of teeth in their children $(p<0.05)$. However, significantly more respondents from the high socioeconomic class reported fewer symptoms in comparison to those from the middle and low socioeconomic classes $(p<0.05)$ and $(p<0.05)$, respectively. However, there was no significant difference between the middle and low socioeconomic classes $(p>0.05)$ (Table 5).

Breastfeeding status $(p>0.05)$ (Table 6$)$ or gender $(p>0.05)$ (Table 7) did not appear to play a role in the reported teething symptoms.

Table 4. Mothers' beliefs on teething according to socioeconomic class.

\begin{tabular}{|l|c|c|c|}
\hline \multirow{2}{*}{ Signs and symptoms } & \multicolumn{3}{c|}{ Socioeconomic Class } \\
\cline { 2 - 4 } & High & Middle & Low \\
\hline Should be no symptoms & 59 & 145 & 156 \\
\hline There are symptoms & 43 & 299 & 304 \\
\hline Total & 102 & 444 & 460 \\
\hline
\end{tabular}

Table 5. Incidence of signs and symptoms of teething in children whose mothers did not believe in teething problems according to socioeconomic class.

\begin{tabular}{|l|c|c|c|}
\hline \multirow{2}{*}{ Signs and Symptoms } & \multicolumn{3}{|c|}{ Socioeconomic Class } \\
\cline { 2 - 4 } & High & Middle & Low \\
\hline No symptoms & $32(54.24 \%)$ & $44(30.34 \%)$ & $48(30.77 \%)$ \\
\hline Symptoms & $27(45.76 \%)$ & $101(69.66 \%)$ & $108(69.23 \%)$ \\
\hline Total & $59(16.39 \%)$ & $145(40.28 \%)$ & $156(43.33 \%)$ \\
\hline
\end{tabular}

Table 6. Signs and symptoms of teething problems in the children according to breastfeeding status.

\begin{tabular}{|l|c|c|c|}
\hline \multirow{2}{*}{ Symptoms } & \multicolumn{2}{|c|}{ Breastfeeding Status } & \multirow{2}{*}{ Total } \\
\cline { 2 - 3 } & Full & Partial & \\
\hline No Symptoms & 188 & 60 & 248 \\
\hline Symptoms & 615 & 150 & 765 \\
\hline Total & 803 & 210 & 1013 \\
\hline
\end{tabular}


Table 7. Signs and symptoms of teething in relation to the children by gender.

\begin{tabular}{|l|c|c|c|}
\hline \multirow{2}{*}{\multicolumn{1}{|c|}{ Symptoms }} & \multicolumn{2}{c|}{ Gender } & \multirow{2}{*}{ Total } \\
\cline { 2 - 3 } & Male & Female & \\
\hline No symptoms & 127 & 121 & 248 \\
\hline Symptoms & 387 & 378 & 765 \\
\hline Total & 514 & 499 & 1013 \\
\hline
\end{tabular}

\section{Discussion}

Most of the mothers in the study, 765 (75.5\%) reported signs and symptoms during eruption of the primary teeth of their children. This is similar to the report of a recent study conducted by Sarrell et al. ${ }^{10}$ in which almost all children in their study experienced problems during eruption. Although controversy exists about teething, the relationship between teething and medical signs and symptoms is generally considered a myth among dental and medical practitioners. Some investigators ${ }^{2-5}$ believe the occurrence of teething problems at about six months of age is related to a decrease in the presence of maternal antibody as the child is generating his or her own antibodies. Others believe teething problems are due to infection or undiagnosed herpetic gingivostomatitis. ${ }^{11}$ Nonetheless, perceptions of teething as a problematic condition still persist.

The study noted a significant association between socioeconomic status, mother's beliefs, and the actual reported signs and symptoms of teething in their children. Mothers in a high socioeconomic status reported significantly fewer signs and symptoms associated with tooth eruption in their children compared to those in the middle and low socioeconomic groups. Their beliefs on teething and associated signs and symptoms was also significantly more positive (they expected less signs and symptoms) in comparison to those from the other socioeconomic groups.

A literature search yielded no reports on the possible direct effect of the socioeconomic class and teething problems. However, sanitation, hygiene, and nutritional standards would be expected to be higher for children from a high socioeconomic class.

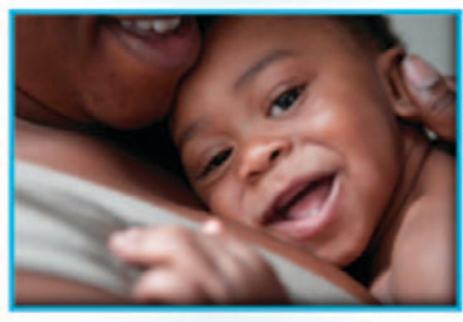

Therefore, these children should be less prone to infection during infancy which may erroneously be ascribed to teething. King ${ }^{11}$ noted the interesting possibility teething symptoms might actually be the result of undiagnosed herpetic gingivostomatitis, a lesion with the symptoms ascribed to teething and with a frequency of occurrence during the tooth eruption period. ${ }^{11}$

The study identified several mothers who had no prior belief there were systemic signs and symptoms associated with teething actually reported having noticed teething symptoms in their children, thus, confirming such beliefs are not solely dependent on observation alone. Education may also be a factor to consider because of the significantly high number of mothers in the study who do not believe in teething problems were from the high socioeconomic class.

Reported signs of fever may not be completely unrelated to teething. Jaber and Cohen ${ }^{12}$ reported a statistically significant increase in temperatures beginning three days before tooth eruption, with the highest temperature recorded on the day of eruption. Macknin et al. ${ }^{13}$ and Tasanen ${ }^{14}$ also reported a high frequency of fever being reported as a teething symptom, but they did 
not report cases of irritability or diarrhea. Wake et al..$^{15}$ found no association between teething, body temperature, or other symptoms including drooling, sleep disturbance, diarrhea, or rashes.

While the present study identified fever as the most frequent symptom attributed to teething, Cunha et al. ${ }^{16}$ and Baykan et al. ${ }^{17}$ reported gingival irritation as the most frequent sign attributed to teething. The present study also found no significant association between breastfeeding status and reported teething symptoms. In addition, no association between a child's gender and reported teething symptoms was found.

Although the information on breastfeeding status depended on the ability of the mothers to recall details of infant feeding practices, this may not be considered as a limitation for the study. Li et al. ${ }^{18}$ defined the reliability and validity of a mother's information recall about infant breastfeeding practices. They noted the reliability and validity of the mother's recall about breastfeeding data was high for the first 36 months which was the window of time during which this data was collected.

\section{Conclusion}

- Most mothers in the study reported signs and symptoms during eruption of primary teeth in their children irrespective of their beliefs.

- Fever was the most common teething problem seen in children by the mothers.

- Traditionally, most mothers believed fever to be the most common teething problem seen in children.

- Parents of children from a high socioeconomic class are likely to report fewer signs and symptoms (teething problems) in their children compared to those from middle and low socioeconomic classes.

\section{Clinical Significance}

Most signs and symptoms adduced to teething by parents may actually be due to underlying infections. Thus, there is a need to rule out occult infection during the tooth eruption period. 


\section{References}

1. Al-Jasser NM, Bello LL. Time of eruption of primary Dentition in Children from Saudi Arabia. J Contemp Dent Pract 2003; 4:65-75.

2. Anderson JE. "Nothing but the tooth": Dispelling myths about teething. Contemporary Pediatrics July 2004; $21: 75$.

3. Bankole OO, Denloye OO, Aderinokun GA. Attitude, beliefs and practices of some Nigerian nurses toward teething in infants. Odontostomatol Trop. 2004; 27:22-26.

4. Denloye O, Bankole OO, Aderinokun GA. Teething myths among community health officers. Odontostomatol Trop. 2005; 28:19-22.

5. Bankole OO, Aderinokun GA, Denloye OO. Evaluation of a photo-poster on nurses' perceptions of teething problems in South-western Nigeria. Public Health. 2005; 119:276-282.

6. Guerini V. A history of dentistry from ancient times until end of eighteenth century. Lea and Febiger, Philadephia, New York 1909.

7. Seward MH. Local disturbances attributable to eruption of the human primary dentition. Br Dent J. 1971; 130:72-73.

8. Seward $\mathrm{MH}$. General disturbances attributable to eruption of the human primary dentition. J Dent Child. 1972a; 39:178-183.

9. Office of the population census and surveys (OPCS). Standard occupational classification 1991; Vol 3 London: HMSO.

10. Sarrell EM, Horev Z, Cohen Z, Cohen HA. Parents' and medical personnel's beliefs about infant teething. Patient Education and Counseling. April 2005; 57:122-125.

11. King DL, Steinhauer W, Garcia-Godoy F: Herpetic gingivostomatitis and teething difficulty in infants. Pediatr Dent 1992; 14:82.

12. Jaber L, Cohen IJ, Mor A. Fever associated with teething. Arch Dis Child 1992;67:233.

13. Macknin ML, Piedmonte M, Jacobs J, Skibinski C. Symptoms associated with infant teething: A prospective study. Pediatrics 2000;105:747.

14. Tasanen A. General and local effects of the eruption of deciduous teeth. Ann Paediatr Finne 1968;14(suppl 29):1.

15. Wake M, Hesketh K, Lucas J. Teething and tooth eruption in infants: A cohort study. Pediatrics 2000;106:1374.

16. Cunha RF, Pugliesa DMC, Garcia LD, Murata SS. Systemic and local teething disturbance: prevalence in a clinic for infants. J Dent Child. 2004; 71(1):24-26.

17. Baykan Z, Sahin F, Beyazova U, Özçakar B, Baykan A. Experience of Turkish parents about their infants' teething Child: Care, Health and Development 2004; 30(4) 331-336.

18. Li R, Scanlon KS, Serdula MK. The validity and reliability of maternal recall of breastfeeding practice. Nutr Rev 2005; 63:103-10.

\section{About the Authors}

\section{Elizabeth O. Oziegbe, BCh.D, FMCDS}

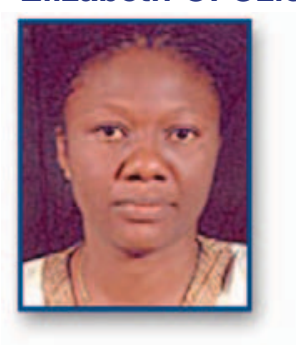

Dr. Oziegbe is a Lecturer/Consultant in Pediatric Dentistry in the Department of Child Dental Health of the Faculty of Dentistry at Obafemi Awolowo University in Ile-Ife, Nigeria.

e-mail: elioziegbe@yahoo.com 
Morenike O. Folayan, BCh.D, FWACS

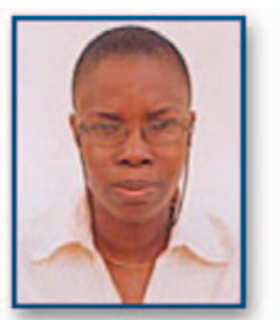

Dr. Folayan is a Senior Lecturer/Consultant in Pediatric Dentistry in the Department of Child Dental Health of the Faculty of Dentistry at Obafemi Awolowo University in IleIfe, Nigeria.

Comfort A. Adekoya-Sofowora, BDS, MDS, FMCDS, FWACS

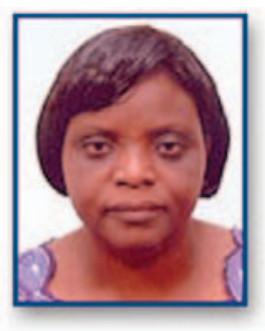

Dr. Adekoya-Sofowora is a Senior Lecturer/Consultant in Pediatric Dentistry in the Department of Child Dental Health of the Faculty of Dentistry at Obafemi Awolowo University in Ile-Ife, Nigeria.

\section{Temitope A. Esan, BCh.D, FMCDS}

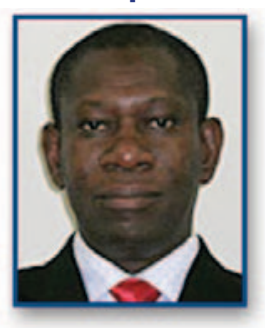

Dr. Esan is a Senior Lecturer/Consultant Prosthodontist in the Department of Restorative Dentistry of the Faculty of Dentistry at Obafemi Awolowo University in IleIfe, Nigeria.

\section{Foluso J. Owotade, BCh.D, FWACS}

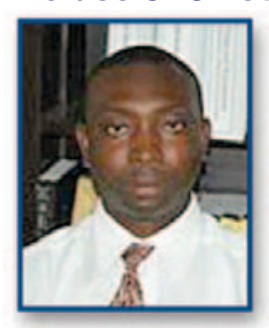

Dr. Owotade is an Associate Professor in the Department of Oral and Maxillofacial Surgery of the Faculty of Dentistry at Obafemi Awolowo University in Ile-Ife, Nigeria. 